\title{
Application of Probabilistic Model for Marine Steam System Failure Analysis under Uncertainty
}

\author{
Sidum Adumene, Samson Nitonye \\ Department of Marine Engineering, Rivers State University, Port Harcourt, Nigeria \\ Email: sidum.adumene@ust.edu.ng,nitonyessamson@gmail.com
}

How to cite this paper: Adumene, S. and Nitonye, S. (2018) Application of Probabilistic Model for Marine Steam System Failure Analysis under Uncertainty. Open Journal of Safety Science and Technology, 8, 21-34.

https://doi.org/10.4236/ojsst.2018.82003

Received: March 14, 2018

Accepted: June 17, 2018

Published: June 20, 2018

Copyright ( 92018 by authors and Scientific Research Publishing Inc. This work is licensed under the Creative Commons Attribution International License (CC BY 4.0).

http://creativecommons.org/licenses/by/4.0/

(c) (i) Open Access

\begin{abstract}
In ship and offshore operations, machinery systems have associated operational hazard because of the prevailing harsh environment. Therefore, the need for an overall evaluation of the associated risk and failures of these systems, such as the marine steam boiler, is crucial to the industry. The concept of probability risk model is used to model the failure mode considering the overall risk associated with the system as a whole. The rate of occurrence of the failure that described the basic events as represented by the fault tree was developed to model the marine steam system. This specific event was implemented and evaluated to estimate the failure frequencies of the overall systems, based on the available failure rate in core literatures. A risk model which is hazard severity weight with its failure frequencies, and the time of operation was applied in the analysis. The probability of failure of the boiler system was estimated at 0.323225 at 35,040 operating hours with hazard severity weight of catastrophic if it occurs. The associated failure frequency calculated for the period is $1.114 \times 10^{-5}$. The over failure frequency of the marine steam system for the period of consideration is conditioned on the pre-defined minimum cut sets of the top event. This therefore agreed with the fact that the basic events with their failure frequencies will lead to the catastrophic failure of the entire system within the period if the maintenance plan is not proactive.
\end{abstract}

\section{Keywords}

Machinery Operation, Marine Steam System, Boiler, Risk, Probability, Failure Mode

\section{Introduction}

Marine steam systems are units that generate steam for electric power generation 
or process heating and operation onboard and other offshore operations. On board ship and in process plant, steam is used for personal uses such as producing heat and hot water. Marine steam system such as boilers contains two basic systems [1], such as the steam water system and the fuel air-flow gas system. Fuel and air served as inputs system, and the process of combustion is done in the wind-box. The boiler outputs systems are the flow gas and ash systems [2]. On board merchant ships, several regulations are required to effectively secure every dangerous part of a ship's machinery to ensure safety of personnel and the ship. Safety remains a human issue, and a human solution has to be found in solving or preventing safety problems [3].

A ship machinery space or engine room is the compartment of the ship where the main engine(s), generator(s), compressor(s), pump(s), boiler plants and other major machineries are located [4]. The ship machinery space where the boiler is located is the most hazardous area of the ship. Despite the fact that marine operations have tended to rely on meeting regulatory requirements, industry codes of practice, or Classification Society Rules, taking all precaution and safety measure while handling engine room machinery system, accident are bound to take place in the ships engine room. There exist specific requirements for machinery in the engine room regarding starting and stopping of the plant. Therefore, strict precaution is needed for boiler system being one of the most important systems on board ships, due to its multipurpose functionality. Although machinery failure is dangerous, some are more dangerous than the other. Therefore, prompt actions on the matter of risk and failure control are crucial in the operation of marine steam systems [5].

Risk-based analysis is used as a monitoring object (condition monitoring, diagnostics and servicing) that integrates technical, economic and safety issues together to provide solution to system problem [6]. Ship operational risks have not been properly defined because of the system complexity, especially in multipurpose carriers, containership. Its evaluation depends on design and construction assumptions, which are burdened with some indetermination of construction solutions. The interaction of hydro meteorological conditions in the ship operating environment, plant maintenance, crew expertise and their habits are contributory factors to the failure or degradation of power system onboard [7]. Risk-based analysis of onboard energy system considers data which includes design data, operational data/efficiency, failure analysis, cost implementation for servicing and repairs

In reference to offshore vehicle as a safe maritime facility, different operation strategies and maintenance methods can be applied to the sub-system to sustain reliability and performance [7]. Therefore, for safe performance and sustainable reliability, it is necessary to ensure flow of mechanical and electrical energy, as well as heat for the sea voyage, loading function, steering and commination utilization. This greatly depend on the main power system consisting the safety of a ship power system in its real operating conditions, the technical, design and op- 
erating parameters are used. The general operating structure as well as sea condition directly influence the required state of any given power system onboard ship [8].

This research seeks to investigate associated risk and failure mode of a steam system that form major part of a marine propulsion system and also for process offshore operations. There exists little research in the area of modeling boiler system risk in the maritime industry and none have applied a probabilistic based technique to predict the trend of the system performance within its design and off-design envelopes. Hence, we proposed the application of a predictive probabilistic tool to model the entire boiler system with the aim to ascertain its failure rate, frequency and consequences for a predefined duration. This provide a novelty application of the probabilistic model in predicting failure characteristic of a marine steam system (boiler plant) which previous literatures did not provide a holistic illustration as is done in this research.

\section{Description of Boiler System Operation for Sea Going Vessels}

The boiler system is configured with feed water drum and the water utilizes the heat energy released by the burning fuel. This energy gained converted the water into the form of steam with very high temperature and pressure. The system has a combustion chamber for the pressurization of the fuel to high temperature and air is supplied to this combustion chamber through a separate arrangement to enhance combustion [9].

Heat exchange occurred from the hot gas to the water through the boiler drum wall of a given large surface area, which enables the highest rate of energy transfer [10]. The energy from the burning fuel is then used for different purpose onboard, such as:

- Steam production for process,

- Steam superheating for power generation.

\subsection{Types of Boiler}

We have two main types of boiler. These two are the basic, all other boiler are different versions of them.

- Water tube boiler,

- Fire tube boiler.

The water tube boiler is a shell and tube heat exchanging system where the exhaust gases are the product of combustion passes over the tubes containing flowing water. Research shown that boiler tubes are made of materials that typically withstand higher internal pressure compare to large chamber shell in a fire tube boiler. For higher temperature application, water tube boilers are mostly used with high steam pressures (as high as $3000 \mathrm{psi}$ ) are required. Water tube boilers performance also show high efficiencies and can generate saturated or superheated steam as the need arises. The merit of water tube boiler to generate 
high pressure steam (superheated steam) makes it attractive in applications for steam turbine power generation [10].

In Fire tube boiler, heat is transferred from the combustion gases pass inside boiler tubes, to the water on the shell side. Fire tube boilers are described by their number of passes configuration. This describes the number of times the combustion (or flue) gases flow the length of the system as they transfer heat to the water [11]. The passes are arranged in a counter-flow pattern. For design configuration, the gases turn 180 degrees and pass back through the shell.

\subsection{General Boiler Hazard}

Over the year risks associated with boiler plant operations has been drawn from the following hazardous situations within the boiler as outline below.

- Control system malfunction;

- Fire;

- Fire side explosion;

- Loss of power supply;

- Loss of water;

- Overpressure;

- Overheating (overheating as a result of low water is the most common cause of boiler damage or explosions, usually a result of the malfunction of the automatic controls);

- Unauthorized access;

- Unauthorized modifications and repairs.

The overall operation and maintenance of boiler plant gives rise to a high level of risk, basically the super heater, boiler water level, boiler furnace fuel and air supply, boiler safety valves and more will be analyzed in this research work. Safety and risk are related. The safer operation is defined as a case of fewer risks. Property damage is considered a risk that might cause injury or loss of life [12]. Current regulations demand the implementation of safety requirements in boiler operation to keep risks under safe control. Therefore, the importance of risk and safety analysis in the operation of ship machinery is key to the safe manning of ships. We have occurrences that can result to failure of steam steams, these includes:

\section{- Melt Down}

Melting down occur when the heating surface metal reach its melting point, which is temperature dependent. This occurs mostly when boiler operating at a very low water level. Although it not results to boiler explosion in itself, but it effects causes major damage to the boiler and create a dangerous situation which could lead to an explosion.

\section{- Thermal Shock}

This is a condition where low water causes the heating surfaces to become overheated and then cooler water is added. The water then flashes to steam which expands 1600 times its volume as water and causes the explosion because 
there is not enough room for the steam to expand.

- Combustion Explosions

These can be a result of gases which build up and an ignition source ignites the gases. This can happen inside the boiler or outside. There are safety devices in place to avoid these situations and we will discuss these in the following slides.

- Steam Pressure

Excessive steam builds up which exceeds the design pressures of the vessel. There is also safety device to prevent this.

\section{Operational Framework for Risk and Safety-Based Assessment}

Power system functionality and effectiveness form a strong hold on the seaworthiness of all oceans going vehicle. Ship power system management involves planning and decision making, organizing, managing and control. This system management from the operational strategy which defines the methods of maintaining the technical condition of an assumed level as in the required time of their operation, often estimated with key indication of effectiveness [7]. This framework entailed Control Based Maintenance (CBM), Planned Maintenance Strategy (PMS), Preventive Maintenance (PM) Reliability Centered Maintenance (RCM) and Time-Based Maintenance (TBM).

Operating maintenance management of ship power system should be carried out in compliance with regulation of the ISM Code, classification solution and the applied operating strategy guaranteeing that the power system will perform the task facing it. The operational approach is justified by the creations of maintenance strategies of technical conditions of ship equipment based on optimizing economic resources on technology and safety [7]. Although control system with failure analysis are been implemented to a limited extent to explain risk-based analysis. In Nwaoha et al. [13], they combined fuzzy logic, ER, and AHP algorithms to assess the propeller operational safety and reliability. The result should degree of confidence in the application of these tools. These provide the categorization of the various threats to the safe operation of the propeller as well as the cost implication on the ship owner. Many maintenance strategies lack reliability base on technical risk. Most times, boiler system failure is one such dangerous accident which is caused because of the following reasons:

- Fuel dripping inside the furnace of the boiler (blowback and even explosion),

- Misfiring,

- Overheating of boiler due to loss of water circulation,

- No pre- and post-purging,

- Exhaust gas boiler fire.

\subsection{Fault Tree Application for Failure Analysis}

Many safety assessment approaches, such as probabilistic risk assessment method, have been widely used but do have some challenges such as reliance on the failure rate data, which may not be available. The fault tree analysis (FTA) is a 
productive hazard analysis technique widely used in the maritime industry [14]. According to Nwaoha et al., [14], FTA is carried out using deductive analysis from the top event, which is the undesired event followed by causal relationships of the failures leading to that event identified by experience from previous accident of the report in question [14]. FTA can be evaluated using both qualitative [15] [16] and quantitative techniques [15] [17]. Similarly, the reduction of FTA can be carried out by the Boolean algebra method [16] [18] and the BDD method [19] [20]. It is important to understand that a fault tree is not a model dealing with all possible system failures and it covers the most credible faults as assessed by the analyst [18]. FTA uses different types of gates for it construction, which makes it a static or dynamic fault tree [21], a non-coherent [22] or coherent fault tree. A coherent fault tree which is mostly used in risk assessment in the marine industry, uses OR and AND gates to construct its tree [14]. Risk modeling of boiler systems in this case, we used FTA because of it compatibility for effective cost modeling and hazard consequences.

Wang and Trbojevic [18] defined Risk assessment as a comprehensive estimation of the probability and the degree of the possible consequences in a hazardous situation in order to select appropriate safety measures. Risk assessment is a useful tool for both the marine and process industry and it can be used to identify areas that need regular maintenance and repair for performance sustainability. Mathematically, risk can be expressed as follows [14]:

$$
\begin{gathered}
\text { Risk }=\text { consequences } \times \text { likelihood } \\
=\text { Hazard severity }(s) \times \text { failure probability }(p) \\
=\text { Hazars severity's weight }\left(S_{w}\right) \times \text { failure probability }(p)
\end{gathered}
$$

In the risk assessment of the marine boiler, failure probability intends to define and follow an exponential distribution path, such that;

$$
\begin{gathered}
P=1-\mathrm{e}^{-\lambda t} \\
\lambda=\frac{-\ln (1-P)}{t}
\end{gathered}
$$

Therefore

$$
R=S_{w} \times\left(1-\mathrm{e}^{-\lambda t}\right)
$$

where

$1-\mathrm{e}^{-\lambda t}$ is the exponential distribution formulas,

$P$ is the failure probability,

$\lambda$ is the failure rate or frequencies,

$t$ is the time of interest.

The basic risk level (basic events) of the whole boiler system can be determined by the sum of the risk associated with its systems.

$$
R_{T}=R_{\text {subsystem(1) }}+R_{\text {subsystem(2) }}+\cdots+R_{\text {subsystem(n) }}
$$

where 
$R_{T}$ is the total risk of boiler system,

$R_{\text {System(i) }}=$ risk of the boiler subsystem $i, \quad i=1,2, \cdots, n$ or $(i \in n)$.

Therefore, by substitution we have the following

$$
R_{T}=S_{w 1} \times\left(1-\mathrm{e}^{-\lambda_{1} t_{1}}\right)+S_{w 2} \times\left(1-\mathrm{e}^{-\lambda_{2} t_{2}}\right)+\cdots+S_{w n} \times\left(1-\mathrm{e}^{-\lambda_{n} t_{n}}\right)
$$

where

$S_{w(i)}$ is the hazard severity's weight of the boiler subsystems $i$,

$\lambda_{i}$ is the failure rate of the boiler subsystem $i$,

$t_{i}$ is the time interest of the boiler subsystem $i$,

$i=1,2,3, \cdots, n$ or $(i \in n)$.

The associated risk which defined the top event of an FTA modeling of boiler system is evaluated using the level/consequences pathway.

Qualitative risk analysis is used identified hazard that can be categorized to be catastrophic, critical, marginal and negligible categories as shown in Table 1. The occurrence probability of the hazards can be expressed as frequent, probable, occasional or remote as the case may be as shown in Table 2. This analysis tends to obtain the level/consequence of risk in the early stage where data are not available for quantitative risk analysis. It is used to analyse each individual component by applying characteristic features such as failure rate, repair rate, system logic, maintenance schedule, mission time and human error. These characterized features are used to formulate a mathematical model which helps to identify high risk areas needed to be controlled. The risk associated with the boiler system and their combined consequence can be represented using combination therapy as indicated in Table 3. Different actions are to be taken to eliminate or control the hazards associated with the plant. These are group as follows [14]:

Table 1. Boiler system hazard consequence.

\begin{tabular}{cccc}
\hline Severity Index & Description & Equipment & Personnel \\
\hline 4 & Catastrophic & System loss & Death \\
3 & Critical & Major system damage & Severe injury/illness \\
& Marginal & Minor system damage & Minor injury/illness \\
1 & Negligible & Non-significant damage & $\begin{array}{c}\text { Non-significant } \\
\text { injury/illness }\end{array}$ \\
\hline
\end{tabular}

Table 2. Hazard probability [14].

\begin{tabular}{ccc}
\hline Level & Description & Equipment \\
\hline A & Frequent & Likely to happen \\
B & Probable & Several times during lifetime \\
C & Occasional & Likely to happen once \\
D & Remote & Unlikely but possible during lifetime \\
\hline
\end{tabular}


Table 3. Boiler system risk assessment matrix [14].

\begin{tabular}{cccccc}
\hline $\begin{array}{c}\text { Hazard } \\
\text { Severity }\end{array}$ & Weight & A (Frequent) & B (Probable) & C (Occasional) & D (Remote) \\
\hline Catastrophic & 1000 & A-01 & B-01 & C-01 & D-01 \\
Critical & 100 & A-02 & B-02 & C-02 & D-02 \\
Marginal & 10 & A-03 & B-03 & C-03 & D-03 \\
Negligible & 1 & & No significant hazards & \\
\hline
\end{tabular}

- Adequate design and operational actions are required to eliminate or control hazards classification as A-01; A-02; A-03, B-01, B-02 and C-01;

- Hazard consequences must be controlled for classification B-03; C-03, and D-01;

- Hazard control is desirable if cost effective for hazard classified as C-03 and D-02;

- Hazard control is not cost effective for hazards classified as D-03.

\subsection{Hazard Identification in Marine Boiler Operations and Probabilistic Analysis}

Potential hazards associated with the boiler system can be identified by experts in the maritime industry. Wang and Trbojevic [18] defined hazard as a physical situation with a potential to cause injuries/deaths, property damage to the environment, or some combination of these. HAZID is carried out from systematic reviews of all operational modes modeling different sections of the boiler plant [14]. The team ensures that the process is proactive and not confirmed only to hazards that have materialized in the past operation. The following hazards were identified on investigation.

A system failure may occur unexpectedly and care is needed for supercritical equipment like the marine steam system. The boiler system failure may be rooted in structural defects, corrosion, stress rupture, fatigue, erosion, and lack of quality control [23]. Stress rupture occurs when the stress cracks and creep set in simultaneously, as a result of thermal overheating that may be long or short terms. This is predisposed by excessive pressure and temperature to pressure relief valve and temperature sensor failure. Fatigue occurs when vibration, thermal stress, and corrosion effect simultaneously set in. These predisposing factors include structural defects, pressure relief valve failure and corrosion [24]. Corrosion causes are critical damage and deformation on boiler material structure, and this occurs as a result of fuel ash, embrittlement, carbide graphitization, dew point, pitting, oxidation and intergranular. Erosion occurs by influence of fly ash, falling slag, soot blower and fuel ash. Lack of quality controls can result from the design, fabrication, operation and maintenance, oxidation, chemical excursion, weld defect and structural defect. Structural defects, temperature sensor failure, pressure relief valve failure, personnel faults, impurities, corrosion are basic events as shown in Table 4 and Figure 1. The Figure 1 is drawn from 
Table 4. Risk/hazard events algorithm coding for marine boiler system.

\begin{tabular}{|c|c|c|}
\hline Major Events & Basic Events & Coding \\
\hline & Stress Cracks & $\mathrm{J} 1$ \\
\hline & Thermal Overheating & $\mathrm{J} 11$ \\
\hline & Temperature Fluctuation & $\mathrm{J} 12$ \\
\hline & Sensor Failure & J111 \\
\hline & Relief Valve Failure & $\mathrm{J} 121$ \\
\hline \multirow[t]{9}{*}{ Stress Rupture (J) } & Creep Failure & $\mathrm{J} 2$ \\
\hline & Overheating & $\mathrm{J} 21$ \\
\hline & Long-Term Overheating & $\mathrm{J} 211$ \\
\hline & Short-Term Overheating & $\mathrm{J} 212$ \\
\hline & Pressure Relief Valve Failure & $\mathrm{J} 2111$ \\
\hline & Temperature Sensor Failure & $\mathrm{J} 2121$ \\
\hline & Vibration & K1 \\
\hline & Defects & K11 \\
\hline & Thermal Stress & K2 \\
\hline \multirow[t]{9}{*}{ Fatigue (K) } & Temperature Sensor Failure & $\mathrm{J} 2121$ \\
\hline & Corrosion Effect & K3 \\
\hline & Material/Structural Defect & K31 \\
\hline & Fireside Corrosion & $\mathrm{X} 1$ \\
\hline & Fuel Ash & $\mathrm{X} 11$ \\
\hline & Personnel Faults & $\mathrm{X} 111$ \\
\hline & Embrittlement & $\mathrm{X} 12$ \\
\hline & Sulfidation & $\mathrm{X} 13$ \\
\hline & General Impurities & $\mathrm{X} 131$ \\
\hline \multirow[t]{10}{*}{ Corrosion $(\mathrm{X})$} & Nucleate Boiling & $\mathrm{X} 14$ \\
\hline & Material Impurities & $\mathrm{X} 141$ \\
\hline & Carbide Graphitization & $\mathrm{X} 15$ \\
\hline & Waterside Corrosion & $\mathrm{X} 2$ \\
\hline & Dew Point & $\mathrm{X} 21$ \\
\hline & Oxidation & $\mathrm{X} 22$ \\
\hline & Formation of Sigma Phase & $\mathrm{X} 23$ \\
\hline & Pitting & $\mathrm{X} 24$ \\
\hline & Intergranular & $\mathrm{X} 25$ \\
\hline & Fly Ash & Y1 \\
\hline \multirow[t]{4}{*}{ Erosion $(\mathrm{Y})$} & Falling Slag & $\mathrm{Y} 2$ \\
\hline & Soot Blowers & Y3 \\
\hline & Fuel Ash & Y4 \\
\hline & Oxidation & $\mathrm{X} 22$ \\
\hline \multirow[t]{3}{*}{ Lack of Quality Control (Z) } & Chemical Excursion & $\mathrm{Z} 1$ \\
\hline & Weld Defects & $\mathrm{Z} 2$ \\
\hline & Material/Structural Defects & K31 \\
\hline
\end{tabular}




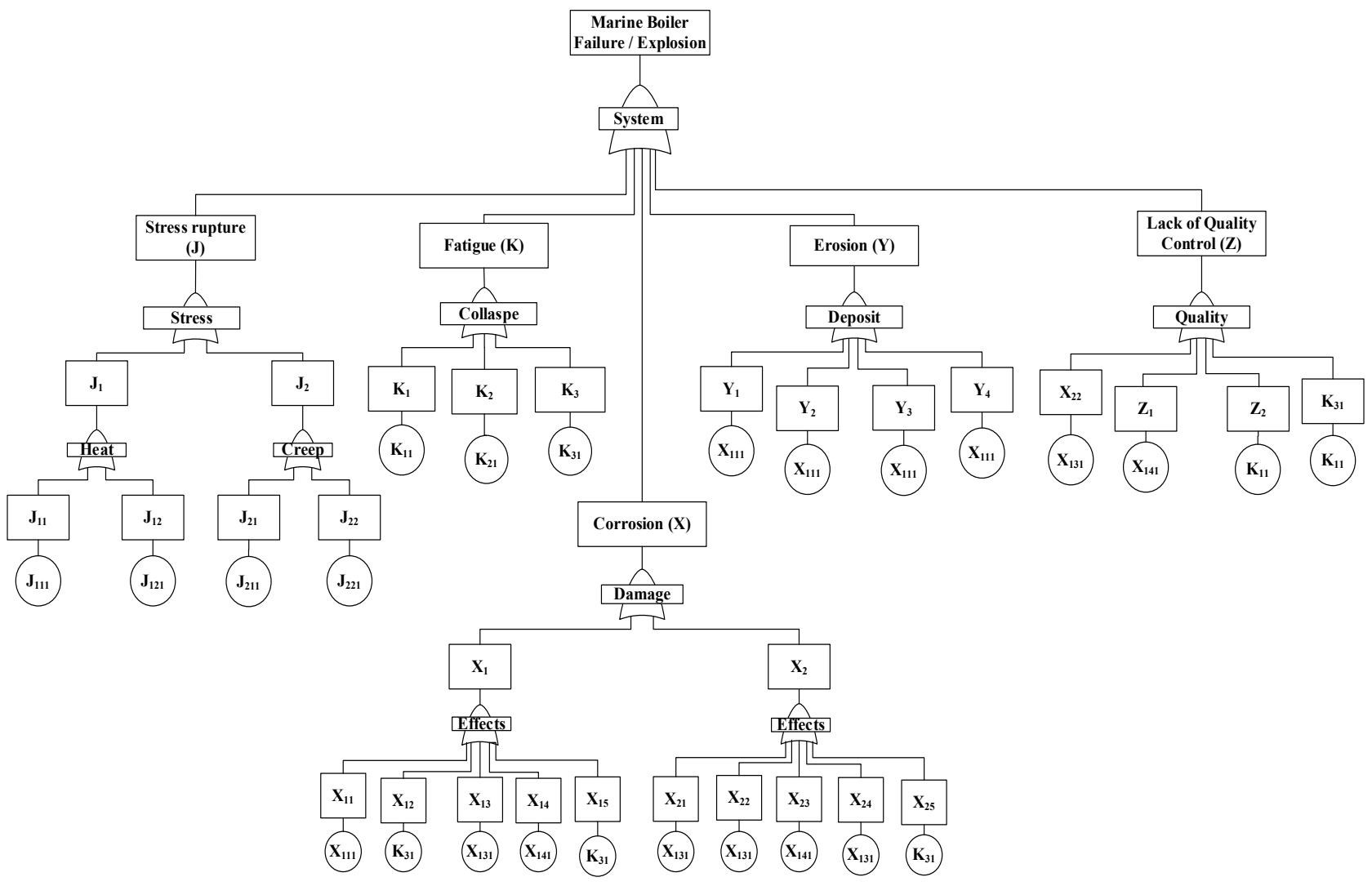

Figure 1. Fault tree of marine steam system failure mode.

the categorization of the prevailing failure mode associated with the case study.

For the quantification of the top event, the marine boiler has five major events with different basic events and their failure consequences. Although the overall basic events are grouped into eight for the purpose of this research and their assigned frequency of failure and probability is shown in Table 5.

For the entire marine boiler system, the failure probability gives

$$
\begin{aligned}
& P(\text { Marine boiler system }) \\
& =P(A)+P(B)+P(C)+P(D)+P(E)+P(F)+P(G)+P(H) \\
& \rightarrow P(A)+P(B)+P(C)+P(D)+P(E)+P(F)+P(G)+P(H) \\
& -P(A) \cdot P(B)-P(A) \cdot P(B)-P(A) \cdot P(C)-P(A) \cdot P(D) \\
& -P(A) \cdot P(E)-P(A) \cdot P(F)-P(A) \cdot P(G)-P(A) \cdot P(H) \\
& -P(B) \cdot P(C)-P(B) \cdot P(D)-P(B) \cdot P(E)-P(B) \cdot P(G) \\
& -P(B) \cdot P(H)-P(C) \cdot P(D)-P(C) \cdot P(E)-P(C) \cdot P(F) \\
& -P(C) \cdot P(G)-P(C) \cdot P(H)-P(D) \cdot P(E)-P(D) \cdot P(F) \\
& -P(D) \cdot P(G)-P(D) \cdot P(H)-P(E) \cdot P(F)-P(E) \cdot P(G) \\
& -P(E) \cdot P(H)-P(F) \cdot P(G)-P(F) \cdot P(H)-P(G) \cdot P(H)
\end{aligned}
$$

And if the boiler is estimated for a 20 years period and is subjected to major failure analysis every four (4) years period, we have

At $t=35,040 \mathrm{~h}$, 
Table 5. Marine boiler system basic events and their failure frequency and probability.

\begin{tabular}{ccc}
\hline Basic Event & Failure Frequency & Failure Probability [14] \\
\hline Structural defects & $2.31 \mathrm{e}^{-006} / \mathrm{h}[25]$ & $\mathrm{P}[\mathrm{A}]$ \\
Corrosion effects & $1.115 \mathrm{e}^{-006} / \mathrm{h}[25]$ & $\mathrm{P}[\mathrm{B}]$ \\
Pressure relief system & $2.12 \mathrm{e}^{-005} / \mathrm{h}[25]$ & $\mathrm{P}[\mathrm{C}]$ \\
Fire and explosion & $1.78 \mathrm{e}^{-006} / \mathrm{h}[25]$ & $\mathrm{P}[\mathrm{D}]$ \\
Overpressure & $0.01 / \mathrm{h}[26]$ & $\mathrm{P}[\mathrm{E}]$ \\
Material defect & $11.15 \mathrm{e}^{-06} / \mathrm{h}[25]$ & $\mathrm{P}[\mathrm{F}]$ \\
Sensor failure & $0.03 / \mathrm{h}[27]$ & $\mathrm{P}[\mathrm{G}]$ \\
Overheating (rupture) & $2.96 \mathrm{e}^{-010} / \mathrm{h}[26]$ & $\mathrm{P}[\mathrm{H}]$ \\
\hline
\end{tabular}

$$
\begin{gathered}
P(A)=1-\mathrm{e}^{-\lambda t} \text { where } \lambda=2.31 \mathrm{e}^{-006} \\
P(A)=1-\mathrm{e}^{-2.31 \mathrm{e}^{-006 \times 35040}}=1-0.922=0.078 \\
P(B)=1-\mathrm{e}^{-1.115 \mathrm{e}^{-006 \times 35040}}=1-0.962=0.038 \\
P(C)=1-\mathrm{e}^{-2.12 \mathrm{e}^{-005 \times 35040}}=1-0.928=0.072 \\
P(D)=1-\mathrm{e}^{-1.78 \mathrm{e}^{-006 \times 35040}}=1-0.940=0.061 \\
P(E)=1-\mathrm{e}^{-0.01 \times 35040}=1-0=1 \\
P(F)=1-\mathrm{e}^{-11.15 \mathrm{e}^{-06 \times 35040}}=1-0.677=0.323 \\
P(G)=1-\mathrm{e}^{-0.03 \times 35040}=1-0=1 \\
P(H)=1-\mathrm{e}^{-2.92 \mathrm{e}^{-010 \times 35040}}=1-0.999=0.001
\end{gathered}
$$

$P$ (Marine boiler system)

$$
\begin{aligned}
= & 0.078+0.038+0.072+0.061+1+0.323+1+0.001-(0.078 \times 0.038) \\
& -(0.078 \times 0.072)-(0.078 \times 0.072)-(0.078 \times 0.061)-(0.078 \times 1) \\
& -(0.078 \times 0.323)-(0.078 \times 1)-(0.078 \times 0.001)-(0.038 \times 0.072) \\
& -(0.038 \times 0.061)-(0.038 \times 1)-(0.038 \times 0.323)-(0.038 \times 1) \\
& -(0.038 \times 0.323)-(0.038 \times 1)-(0.038 \times 0.001)-(0.072 \times 0.061) \\
& -(0.072 \times 1)-(0.072 \times 0.323)-(0.072 \times 1)-(0.072 \times 0.01) \\
& -(0.061 \times 1)-(0.061 \times 0.323)-(0.061 \times 1)-(0.061 \times 0.001)-(1 \times 0.323) \\
& -(1 \times 1)-(1 \times 0.001)-(0.323 \times 1)-(0.323 \times 0.001)-(1 \times 0.001) \\
= & 0.323225
\end{aligned}
$$

$$
\begin{gathered}
P(\text { Marine boiler system })=1-\mathrm{e}^{-\lambda_{1} \times 35040} \\
\mathrm{e}^{-\lambda_{1} \times 35040}=1-0.323225 \\
-\lambda_{1} \times 35040 \times \ln \mathrm{e}=\ln 0.6768=-0.39038 \\
\lambda_{1}=1.114 \times 10^{-5}
\end{gathered}
$$

The probability of failure of the boiler system is 0.323225 at 35,040 operating hours with hazard severity weight of catastrophic if it occurs. The associated 
failure frequency $\lambda_{1}$ calculated for the period is $1.114 \times 10^{-5}$.

The over failure frequency of the marine steam system for the period of consideration is conditioned on the minimum cut sets of the top event. This therefore agreed with the fact that when the basic events occur with their failure frequencies, it will lead to the catastrophic failure of the entire system if the maintenance plan is not proactive.

\section{Conclusions}

The process of assessing the associated failure trend in a marine steam system is crucial for every offshore operation. This assessment provides knowledge for improving the level of safety (reduction of risk) in boiler operation. The research focuses on the areas of high risk in steam supply and the major causative events such as stress rupture, fatigue, corrosion, erosion and poor-quality control.

The total risk of the system was analysed mathematically from the probabilistic model. The model estimates the various safety levels of the failure mode by setting up severity and consequences based on the prevailing events. The captured safety level of the subsystems was integrated into the model and the risks were ranked using the prevailing operating condition of the system. The sub-events for the purpose of this research were integrated under the five major events with their failure frequencies from existing literatures. The result shows that the adopted probabilistic model can be used for modeling the failure and risk associated with marine steam systems. This research did not consider the cost implication for the maintenance of the failed subsystems of the overall steam system. This research is not exhaustive. Further work can be done by employing fuzzy based model and evidential reasoning to analyse the professional perfectives on the relative severity classification and modeling.

\section{Acknowledgements}

We sincerely acknowledged Mr. Ezenwoke Anwurike Roy of the Department of Marine Engineering on his contribution to the improvement of this research work.

\section{References}

[1] Edward, A.C., Adumene, S. and Nitonye, S. (2016) Design Modeling and Performance Optimization of a Marine Boiler. World Journal of Engineering Research and Technology, 2, 44-58.

[2] Liptak, B. (2006) Process Control and Optimization. 4th Edition, Taylor and Francis Group, United States of America.

[3] Boisson, P. (1999) Safety at Sea: Policies, Regulations \& International Law. Bureau Veritas, Paris.

[4] Adumene, S. and Nitonye, S. (2016) Assessment of Site Parameters and Heat Recovery Characteristics on Combined Cycle Performance in an Equatorial Environment. World Journal of Engineering and Technology, 4, 313-324.

https://doi.org/10.4236/wjet.2016.42032 
[5] Raunek (2009) Marine Insight. http://www.marineinsight.com

[6] Adamkiewicz, A. and Janusz, F. (2013) Application of Risk Analysis in Maintenance of Ship Power System Elements. Scientific Journals of the Maritime University of Szczecin, 36, 5-12.

[7] Adamkiewicz, A. and Burnos, A (2009) Influence of Maintenance Strategies on the Reliability of Gas Turbine in Power Systems of Floating Production, Storage and offloading Units. 28th International Scientific Conference on DIAGO, Ostrava, 2009, $5-13$.

[8] Nitonye, S., Adumene, S. and Howells, U.U. (2017) Numerical Design and Performance Analysis of a Tug Boat Propulsion System. Journal of Power and Energy Engineering, 5, 80-98. https://doi.org/10.4236/jpee.2017.511007

[9] Samson, N. (2017) Numerical Analysis for the Design of the Fuel System of a Sea Going Tug Boat in the Niger Delta. World Journal of Engineering Research and Technology, 3, 161-177.

[10] Taylor, D.A. (1996) Introduction of Marine Engineering. Butterworth-Heinemann, Oxford.

[11] Ogbonnaya, E.A., Orji, J.C., Ugwu, H.U., Poku R., and Samson, N. (2014) Condition Monitoring and Fault Diagnosis of a Steam Boiler Feed Pump. International research journal in Engineering, Science and Technology, 11, 13-21.

[12] NFPA (2011) NEPA 85: Boiler and Combustion System Harzard Code. National Fire Protection Association, Quincy.

[13] Nwaoha, T.C., Andrew, J. and Adumene, S. (2015) Incorporation of Novel Model in Failure Analysis of Propeller Operations of Sea Going Vessels. Ships and Offshore Structures, 12, 9-18. https://doi.org/10.1080/17445302.2015.1099226

[14] Nwaoha T.C., Yang, Z., Wang, J. and Bonsall, S. (2010) Application of Genetic Algorithm to Risk-Based Maintenance Operations of Liquefied Natural Gas Carrier Systems. Proceedings of the Institution of Mechanical Engineers, Part E: Journal of Process Mechanical Engineering, 225, 40-52. https://doi.org/10.1243/09544089JPME336

[15] Norman, B.F. (1987) Reliability Engineering for Electronic Design. Marcel Dekker Incorporated, New York.

[16] Pillay, A. and Wang, J. (2003) Technology and Safety of Marine Systems. Vol. 7, Elsevier Ocean Engineering Book Series, Oxford.

[17] Desmond, N.D.H. and Gregory, B.B. (2004) Risk and Uncertainty in Dam Safety. Thomas Telford Ltd., London.

[18] Wang, J. and Trbojevic, V.M. (2007) Design for Safety of Marine and Offshore Systems. Institute of Marine Engineering, Science and Technology, London.

[19] Bartlett, L.M. (2000) Variable Ordering Heuristics for Binary Decision Diagrams. Doctoral Thesis, Loughborough University, Loughborough.

[20] Bartlett, L.M. and Andrews, J.D. (2002) Choosing an Ordering Heuristic for the Fault Tree to Binary Decision Diagram Conversion Using Neural Networks. IEEE Transactions on Reliability, 51, 344-349. https://doi.org/10.1109/TR.2002.802892

[21] Amari, S., Dill, G. and Howald, E. (2003) A New Approach to Solve Dynamic Fault Trees. Proceedings of the Annual Reliability and Maintainability Symposium, Tampa, 27-30 January 2003, 374-379. https://doi.org/10.1109/RAMS.2003.1182018

[22] Takehis, K. (2006) A Simple Method to Derive Minimal Cut Sets for a Non-Coherent Fault Tree. International Journal of Automation and Computing, 3, 151-156. https://doi.org/10.1007/s11633-006-0151-4 
[23] Harvey, J.F. (2008) Enhancement of Operational Safety of Engine Room Machinery through (CBT).

[24] Frederick (2013) High Pressure Boiler. American Technical Publishers, Orland Park.

[25] SINTEF (2002) Offshore Reliability Data (OREDA). A Handbook Prepared by SINTEF Technology and Society on the Behalf of the OREDA Project, 4th Edition.

[26] Hyo, K., Jae-Sun, K., Youngsoo, K. and Theofanius, G.T. (2005) Risk Assessment of Membrane Type LNG Storage Tanks in Korea-Based on Fault Tree Analysis. Korean Journal of Chemical Engineering, 22, 1-8. https://doi.org/10.1007/BF02701454

[27] Risknology (2006) Failure Rate Data to the Independent Risk Analysis of the Cabrillo Port LNG Deepwater Port. A Report Prepared for U.S. Coast Guard Agency. 